\title{
Making Communication Strategy Choices in a Fast Evolving Crisis Situation-Results from a Table-Top Discussion on an Anthrax Scenario
}

\author{
Aino Ruggiero \\ Department of Communication, University of Jyväskylä, P.O. Box 35, Jyväskylä FI-40014, Finland; \\ aino.ruggiero@jyu.fi; Tel.: +358-40-805-4830 \\ Academic Editor: Zahera Harb \\ Received: 30 December 2015; Accepted: 6 May 2016; Published: 13 May 2016
}

\begin{abstract}
This paper aims at clarifying a timely topic of how communication strategy choices are made in evolving, complex crises, such as those caused by terrorism involving chemical, biological, radiological, or nuclear (CBRN) agents. This is done by examining data gathered from a table-top discussion among crisis communication experts, focusing on a scenario of an anthrax attack and analysed qualitatively. The communication experts followed the evolving crisis situation by gathering inputs from various actors in the crisis management network, thereby creating situational understanding, and interpreted these inputs for decision-making on communication strategies. The underlying process of coping with complexity in evolving CBRN terrorism crises can be described as a continuous, dynamic process that can best be explained with a combination of traditional and more modern crisis communication approaches. Strategy-making in crisis situations by communication experts is still largely a black box. In this study, a novel approach of decomposing strategy-making by observing a table-top discussion is chosen to clarify the process. By identifying the core elements involved, a more detailed picture of communication strategy-making is created, thus promoting preparedness and professional resilience in the field.
\end{abstract}

Keywords: communication strategies; crisis communication; terrorism

\section{Introduction}

Today's crises are described as complex and challenging, and are thus different from those of the previous century [1]. These new kinds of crises do not have clear boundaries of space and time: they emerge suddenly and spread in unforeseen ways and directions beyond local, functional, and geographical domains [2]. Global terror networks constitute one source of these new kinds of risks [3], as the November 2015 Paris and March 2016 Brussels terrorist attacks also show. The intensified awareness of terrorist risks in the period following the 9/11 attacks has also provoked increased concern over new forms and means of terrorism [4], including the use of biological agents or other CBRN (chemical, biological, radiological, or nuclear) materials for a terrorist purpose.

The aim of this study is to investigate communication strategy-making in evolving, complex crises, such as those caused by terrorism involving CBRN agents. In particular, the focus is on how communication experts cope with complexity and keep track of such situations and make strategy choices. This goal is approached by examining empirical data collected in a table-top discussion on a scenario of an anthrax attack conducted among crisis communication experts and analysed qualitatively. From a communication practice perspective, the findings create understanding on communication strategy-making during an evolving crisis and so help promote communication preparedness for coping with such emergencies. From a theory point of view, studying communication strategy-making in an ongoing crisis situation adds insight into an area which has been little studied, namely the process underlying decision-making on communication strategies during crises [5]. 


\subsection{Communication and CBRN Terrorism}

Communication supports crisis management by public organisations in various ways, including creating understanding of risks and the crisis events; promoting preparedness activities and self-efficacy during a crisis; and creating cooperation in the response network, which comprises citizens, response organisations, and the media [6]. Hence, from a functional perspective, the role of communication is to achieve certain goals or outcomes [7]. Different areas of activities targeted at achieving such goals include monitoring of stakeholder needs, communication with stakeholders, and cooperation in the response network on, for example, coordination and planning [6]. From an integrated process perspective [8], communication in risk and crisis situations concerns the different phases of crises, from preparedness to recovery. Moreover, crisis communication is an ongoing process of creating shared understanding and meanings among and between stakeholders [7]. Given the fact that crisis response in today's society is characterised by a network of multiple response actors [2], a network approach to crisis communication is essential (e.g., [9]).

According to some authors, complex crises, such as those involving terrorism, cannot be explained by the traditional crisis communication theories [10]. What makes terrorism special is intentionality instead of an accidental origin, the uncontrollability of the risks involved, the potential to create widespread harm and damage, including individual risks becoming systemic risks, and the potential to undermine trust and cultivate mistrust in society, leading to a self-multiplication of risks and simplified images of the enemy [3]. In the case of CBRN terrorism, the above is further complicated by CBRN aspects of such crises [11]. A particular feature of CBRN terrorism is the sheer diversity of crisis types to prepare for, scientific uncertainties involving quickly-evolving information, no clear boundaries of time and geographical space, involuntary exposure, and lack of knowledge among public groups $[11,12]$. As a consequence, strong reactions may be created among citizen groups due to the multiple factors pertaining to the risk perceptions that are triggered [13]. These include emotional reactions, such as fear or anxiety, and behavioural responses that may place people in greater danger than the original crisis event itself [14]. This is a challenge for communication.

Mapping risk perceptions [15] and monitoring them prior to and throughout terrorism events, including traditional news media analysis and opinion polling [16], but above all social media monitoring [17], are thus of primary importance. This is in line with the social amplification of risk model [18], according to which communication does not take place in isolation from the societal context, but should be based on an analysis of multiple psychological, social, institutional, and cultural processes [12,16], including multiple public groups with diverse needs [6]. Preparing for CBRN terrorism crises can be included in an all-hazard approach [19], to avoid increasing anxiety and strengthen resilience [15]. In the case of an ongoing event, the role of communication is, for example, to share up-to-date information about that event, instructing publics on precautionary measures and reassuring them [16], including not only directly involved groups but also the larger, indirectly affected, population. In the aftermath of the crisis, communication can help recovery efforts by, for example, empowering people, helping restore trust [20] in a shaken value system by establishing a vision for the future, and facilitating the healing process [21] and learning.

A full review of communication in the case of terrorist incidents is provided elsewhere [11]. In the present paper, the focus is on communication strategy-making by public authorities for communication with different stakeholders, citizen groups in particular, in the context of CBRN terrorism.

\subsection{Communication Strategy Choices}

Due to the urgency of crisis events, and of CBRN terrorism in particular, these situations call for quick and timely actions. Communication strategies can be understood as decision-making rules or recipes for reaching communication goals [22] and solving problems [23], or, in the case of crises, those of crisis management. In this study, the focus is on the process of making communication strategy choices, not the strategies as such. 
The choice of a communication strategy requires a careful analysis of the situation it aims to resolve [22]. To act quickly, the crisis communication team must make a situation analysis and identify which facts in what otherwise may be an overflow of information are critical for public groups [20]. This calls for a variety of monitoring activities, including news media analysis, public inquiries, poll data, and analysis of social media (see [17]) to determine the public's information needs and, for example, where people are located [24]. The purpose of the analysis is to create situational awareness, which is a prerequisite for decision-making: once there is understanding of the crisis situation at hand, the crisis team can better estimate its effects and decide on the actions needed [5].

Decision-making that is based on an analysis of situational information in a rapidly changing environment is in line with more recent approaches to crisis management and communication, which emphasise, for example, complexity (e.g., [25]) and the art of improvisation and networking [26]. These perspectives also apply to terrorism crises, which are characterised by dynamic and diffuse processes and a need for fast adaptation to changing circumstances, and thus challenge the traditional ways of planning and information processing [10]. While most scientists would agree that the new world of risks and crises requires new ways of understanding and handling them (e.g., [1,2]) where linearity of communication has been replaced by the process approach of continuous action and interpretation [26], how the process of making strategy choices in this new context unfolds, is still largely a black box.

This paper consists of five parts. Following the introduction, the method is explained, including data collection, analysis, and background information on the participants. Section 3 presents the findings of this study, Section 4 consists of a discussion, and Section 5 concludes the paper.

\section{Method}

The aim of this paper is to clarify how communication experts cope with complexity in evolving and complex crisis situations, such as those involving CBRN terrorism. In particular, the aim is to find out how experts follow an evolving situation and how they arrive at decisions about the communication strategies to employ in complex crises. The research questions are as follows:

RQ1 How do communication experts follow a rapidly evolving and complex crisis situation?

RQ2 How do communication experts decide on the communication strategies to implement in such crises?

\subsection{Data Collection}

The data for this study were gathered from a table-top discussion that formed part of a workshop organised in Berlin in March 2014 in connection with the international project CATO (CBRN Crisis Management, Architecture, Technologies and Operational Procedures). The workshop comprised three parallel sessions where policy and decision-makers, health responders, and communication experts gathered to discuss CBRN crisis management issues from different perspectives. This article is based on data gathered from the workshop conducted among the communication experts.

The purpose of the workshop was two-fold. It aimed on the one hand at gathering input for communication guidelines and other materials produced for the purposes of the project, while on the other hand aiming at gaining insights for scientific purposes on communication strategy-making in complex crises, such as CBRN terrorism crises. This paper focuses on the data gathered in pursuit of the latter aim. As CBRN terrorism events are rare, a table-top discussion was considered an appropriate venue for data gathering. Moreover, in comparison to interviews, for example, observation of experts' actions was considered to produce more reliable results than simply asking them questions. Seven experts from five different European countries took part in the workshop. They were selected using a purposive strategy (e.g., [27]). The main selection criteria included (1) expertise in the field of crisis communication and (2) experience of CBRN issues and/or strategic communication.

The table-top discussion was organised in consecutive sessions, simulating an escalating crisis. Each session lasted approximately one hour and was preceded by an introduction in which the 
scenario timeline and most important events pertaining to the session in question were explained. The task of the communication experts was to discuss any communication issues that they considered relevant. The discussion was led by three moderators, two whose task was to enable the experts to express themselves freely, while the third took notes. Only a few intermediary questions and comments were posed if, for example, the discussion got stuck on one point or further clarification was deemed necessary.

A fact sheet on anthrax was provided as support material. Moreover, a social media platform with a simulated stream of social and news media feeds was projected on the wall with the purpose of providing further input and to stimulate discussion. The discussion was both tape-recorded and videotaped with a panorama camera allowing a $360^{\circ}$ overview of all the participants simultaneously. Moreover, two researchers observed the discussion and took notes. Following the principles of ethical research, an informed consent form was signed by all the participants before the workshop began.

The table-top discussion was based on a scenario of an evolving anthrax attack. The scenario was developed by a senior consultant on global health security and bioterrorism together with researchers and CBRN specialists working for the project. The scenario timeline was in three parts according to the phases of a crisis: (1) warning; (2) response; and (3) recovery. The first sequence focused on the warning phase and initial impacts, and included the first few hours of the crisis with a period of uncertainty. To begin with, the participants were shown two news items reporting a situation in Brussels where 14 employees of the European Parliament had been admitted to hospital. Two persons had died and a diagnosis of anthrax was being considered, including speculation on the possibility of a bio-terrorist attack. The second sequence, pertaining to the response phase, illustrated the situation on the next day, including the spread of the disease and an increase in the number of victims to over 1000 with 250 deaths. This phase was also marked by problems of access to health facilities and hospitals, fears among the population with many trying to leave the city, overwhelmed transport hubs and much confusion concerning the situation. The third sequence focused on the recovery phase, at day five, at which point many had died, while a large part of the population were still in the contaminated area. Moreover, questions were being asked by different publics concerning medical care, food, and water. Emergency responders were worried, and there were also significant international concerns, including offers of assistance from other countries.

\subsection{Experts' Background Information}

Seven communication experts took part in the table-top discussion. They came from five different European countries: Belgium (1), the Netherlands (2), Norway (2), Romania (1), and Sweden (1). The participants included two crisis communication experts, an EU project researcher with NATO experience, a senior project manager, a senior communication advisor, a press officer, and a communications director. Six of the seven participants were women. The experts were invited on the basis of their extensive experience, ranging between 6 and 18 years, in the field of crisis communication and management.

\subsection{Data Analysis}

First, the recorded video tapes were transcribed. In the next step, the transcripts were read through and colour-coded according to the research questions. The colour-coded rtf files were then exported to ATLAS.ti (version 7) qualitative data analysis software (by Scientific Software Development GmbH, Berlin, Germany) for further analysis.

The analysis was conducted drawing mainly on thematic analysis (e.g., [28]). This was done following both deductive and inductive approaches; the research questions and the structure of the workshop created a basis for analysis which was further complemented by open coding of the discussion. First, in ATLAS.ti, the colour-coded text segments which contributed to the two research questions were further coded. This was done per phase, as each workshop session, representing a different phase of the crisis, was covered in a separate document. After this, the coding was further 
refined with the help of the colour-coded transcripts in Word, including a large table in which the running transcripts were accompanied by all the codes to see the overall evolution of the discussion across the three sessions.

Next, with the help of the network view of ATLAS.ti, all the codes were brought together in an overview. Codes were grouped according to the research questions and further segmented and categorized, following principles of inductive thematic coding and analysis, in order to capture key concepts and themes and underlying patterns [29]. During this process, the codes were also further streamlined, as new codes were created and overlapping ones discarded. Finally, the resulting main themes and topics were brought together and listed in a separate word file. These are described in the next section along with illustrative quotations from the participants' speech.

\section{Results}

In this section, the main findings of this study, based on the analysis of the empirical data gathered via the table-top discussion on the scenario of an anthrax attack, are reported. The discussion had an atmosphere of urgency and engagement, and was lively. Owing to the open structure of the discussion, the experts were able to take many different directions in addressing the communication issues they deemed relevant. Their high level of expertise provided fertile ground for the discussion. Perhaps due to their different backgrounds, both professional and cultural, disagreements also arose at times. Nevertheless, rather than remaining in contradiction, these conflicting views ultimately complemented each other, producing rich data.

Below, the results are summarized and some illustrative quotes are presented. Section 3.1 offers answers to the first research question by explaining how the communication experts followed the evolving situation. Section 3.2 focuses on the second research question and describes how the participants made communication strategy choices in the course of an evolving crisis situation.

\subsection{Following the Situation}

Throughout all the phases simulated in the table-top discussion, the communication experts tried to keep track of the situation and the evolving crisis event by gathering input and creating situational understanding with those inputs.

\subsubsection{Gathering Input}

Gathering input is an ongoing process. In order to monitor the evolving situation, the communication experts expressed a need for information, which is especially pressing at crisis onset. Moreover, the gathering of information and other input is described as a process where giving and receiving alternate:

"[ ... ] we gather information, two things, we are monitoring the outside world, and we are gathering all the information which come from us, from experts, and from other people, so we have an information manager, outside, inside, and we bring it together, from the information we go to a strategic level, we think what are we going to give back, strategic thing $[\ldots]]^{\prime \prime}(\mathrm{P} 3)$

Often the information that they need is something the other actors in the response network possess. The party that they most need liaison with is health experts. The information needs from health responders included, for example, the incubation time of the disease, possible spread and risk zone, the number of victims, decontamination procedures, available treatments (e.g., antibiotics vs. vaccination), including their availability and sufficiency, and health advice that could be provided to public groups.

"I think one of the big challenges will be to get the advice from the health group, like how you should deal with all the clothes and everything, to be as simple, as clear, so that everyone learns it, like three basic advices about [ ... ]" (P2) 
Moreover, information is needed on the health responders' actions and decisions, such as evacuation from or quarantine in the city where the attack took place, and the overall health strategy.

Information is also needed on related crisis management decisions and views regarding, for example, closing off the subway stations, and the level of threat and the risk of repetition. Moreover, the experts' own networks also serve as a route for exchanging information:

"There is such a thing as the health communicators' network from [a name of an institution], I'm a member of it, so in a crisis situation like this, we would activate that, and, and give each other information, so if something like this is going on, we immediately get information [ ... ]" (P5)

However, one of the experts stressed that in addition to information from other experts, the communication experts also gather their own information:

"[ ... ] I think we have a double role, we are not only waiting for information from them, we are going to gather our own information, and that's what, how is it landing in the world, first in Brussels, in politics [ . . . ]" (P3)

\subsubsection{Creating Situational Understanding}

In their attempt to understand the evolving crisis, the participants went through and listed what they know about the situation. As by day two of the crisis case, the response phase, some of the uncertainties have been resolved and more facts can be listed, the creation of situational understanding is easier than in the warning phase.

"[... ] now we know a lot, we know where, we know how it worked, and if you, maybe, we also can say, we stopped it, I mean it has affected most people, and probably because of incubation time lots of people will get ill and even more will die, but we have the source right now $[\ldots]^{\prime \prime}(\mathrm{P} 5)$

One expert pointed out that there are two levels of analysis: "[ . . ] one is the level we know now, and the other level is what can we expect." (P3)

Moreover, the participants sought to further understand the crisis case at hand looking at it from different angles. For example, they identified it as an international case which needs communication across borders. Regarding the risk type, it was concluded that since the bacterium itself is not contagious, infection is possible only through direct exposure to the source or the spores. There is a sense of urgency and uncertainty caused by the potential terrorism aspect of the crisis which can be seen in the social media stream of public discourse:

"Symptoms and terrorists, these are the most common words, symptoms and terrorists, this is uncertainty case." (P7)

Stakeholder analysis is something that needs to be done both initially, and also as the crisis evolves, and includes the identification of relevant publics:

"What we have to do at this stage is that we identify the publics, and one of the most important publics here is international community [ ... ]" (P7)

Moreover, public information needs need to be analysed, which also guides communication. Regarding public groups, analysis of public discussion and publics' perceptions, reactions and concerns were also mentioned:

"[ ... ] what you see is that outside the organisation, you see a lot of public worries." (P3)

"This is risk perception, and we know from all our studies that anthrax and bio is the [shows with her hands: the biggest thing]." (P1) 
Analysing social and news media is a way for communication experts to gather their own information and to find out what people are thinking in order, for example, to formulate strategic advice and to correct inaccuracies.

From the information that the experts have gathered or received, they also identify issues that may need to be addressed in their communication. Some of these relate to practical matters, such as transportation or treatment, others to more intangible issues, such as emotional response in society:

"And I also think we have to remember that two very different kind issues have to be communicated, one thing is the practical thing with the infrastructure and people getting out and in, and want hospital treatment and everything, but the other one is their feeling of safety, I mean this is a threat to the country, and how does that impact people, and what do they need to know to be sure that if it is gonna happen again or where can I be safe in my country, it's two very different type of issues to communicate, I think." (P2)

Other issues mentioned include the risk of repetition, having enough vaccination, prioritisation of treatment, problems of triage, mourning in the risk zone, the image of the attacked city, inadvisable self-evacuation, long-term risk of contamination, people who do not get the right information in time, problems related to insurances, disruption of families, large numbers of victims and the blame game about who is responsible.

Other ways of working with the information gathered cover verifying the source and the information that is provided in the news by, for example, comparing different sources. This relates mainly to the early phase of the crisis, when the experts do not yet have official information on the nature of the attack:

“[ ... ] the most important to start with is, is never a journalistic article about something, you know if you're responsible for communication, you get this, you take this information that you got as a rumour, and you have to check it, and then you get a real original source of the information, you get an access to the primary sources of information [ ... ]" (P7)

By trying to understand the situation, meanings are further clarified, referred to by one expert as "sense-making". Considering different scenarios and comparing the situation at hand with previous cases is commonplace in the later phases of response and recovery. Worst-case scenarios are analysed, for example, with regard to the possible terrorist origin of the crisis:

“[ $\ldots$.. ] if the police have three suspects for this [ ... ] you have to think about the worst case scenario, you have to think ahead [ ... ]" (P2)

The list of cases referred to by the participants in their efforts to find points of comparison with earlier crises was wide, ranging from H1N1, the Marburg virus, tsunami, Q fever, 9/11, the Qoiânia accident and the poisoning of Alexander Litvinenko to the London bomb attacks in 2005. On the need to reassure the public, 9/11 was mentioned:

"[ ... ] like you know the, after the 9/11, the president says we are going to stand together, and all that kinds of messages to the, to the population of Brussels, to keep calm and carry on, you know, who will give that kind of message [ ... ]" (P2)

\subsection{Making Communication Strategy Choices}

Communication experts make strategy choices by interpreting the diverse inputs that they have gained at various points during the evolving crisis event. They consider situational information from different sources, consider effects and scenarios, prioritise issues, weigh goals and principles, and balance their choices with the help of preparedness plans, roles, and responsibilities.

\subsubsection{Interpreting Diverse Inputs}

Choices based on an analysis of the situation include those based on information gathered by analysing the outside world, such as information on the needs and perceptions of different affected publics: 
"[ ... ] do you think that people want to have a memorial, I am not saying that I don't agree, but I say that you have to read the outside world, and then come with you communication, communication actions $[\ldots]$ ]" (P3)

Moreover, the decisions made by communication experts are guided by the actions and decisions of other actors in the crisis situation and the information they have provided regarding, for example, the type of risk in question. When discussing the formulation of messages concerning long-term risks, one expert stated:

"This message must be based on what we hear from our colleagues from health but also from policy and decision makers because maybe, health department, or maybe some kind of ministry says okay, everybody who is a victim will get a thousand euros, we don't know that." (P5)

What weighs more heavily in the balance-the situational analysis obtained from other actors or an analysis of, for example, social media by the communication experts themselves-is not always clear and varies from one expert to another. One expert put it thus:

“[ ... ] what for me is a problem because we are all experts, but we are not acting now based on what is the sentiment in the community of this moment, and that information I am missing now. [ ... ]" (P3)

\subsubsection{Timing and Stakeholder Needs}

What seems to matter a great deal in the process of making strategy choices is timing, which was mentioned by many of the experts:

"Also timing is really important, when do you release these fact sheets [ ... ]. If you release them too early, then you may make panic, you know, you have to be really careful for the timing." (P7)

As a prerequisite for timely communication, roles and responsibilities should be clear, including a mandate for independent action by the communication experts:

“[ ... ] we should have to say that communication officers always should be ready to communicate without any special statements from the decision makers because maybe it will take another day before they confirm it's anthrax, maybe it takes another day before they confirm that it's two dead, but we still have to communicate something, that's the same problem in all the crises." (P2)

Stakeholder analysis, who the relevant stakeholders are and what they expect, guides the strategy-making process from preparedness to recovery, including, for example, defining risk groups, and targeting those who are directly or indirectly affected. In a situation where risk groups have not yet been defined:

“[ ... ] now strategy is be open, direct, mass, because we don't know who were at that place at that time $[\ldots]^{\prime \prime}(\mathrm{P} 3)$

Moreover, public communication should be based on the information needs and previous knowledge of the publics:

“[ ... ] maybe we should start by giving information to the public about what is anthrax because anthrax is well-known for terrorist attacks [ ... ] but I don't think many people will know actually what it is [ ... ]" (P5)

Sometimes security concerns and classified information restrict what can be communicated to the publics and overrule the latter's information needs. 
A factor that may change over the various phases of a crisis is the scale of the crisis and the level on which to conduct communication activities, which can range from the international to the national level, and from the central government to the regional and local level. Regarding recovery efforts and communication one participant suggested:

"And we have to decrease the level from which do we communicate in this case, it's not anymore from the government level, but I would suggest, I don't know maybe to establish one agency or one group [ ... ] to take care over for all these questions." (P7)

\subsubsection{Considering Effects and Scenarios, Prioritising Issues}

In the process of making choices about communication actions to be taken, the participants spent a lot of time weighing the effects of their possible actions when, for example, providing information to the public:

"[ ... ] transparency-if we have information that is important to the public, we share it directly, but we think about the effects of that information, so we give it in the form that is suitable for the different stakeholder groups." (P3)

The effects that were given most consideration included those on the health sector as a result of people's behavioural response to the crisis. Regarding the release of information on anthrax and its possible treatment, it was pointed out:

“[ ... ] we have to be really sensitive toward what kind of general information about anthrax we're going to release, because, for instance, if you release the information that antibiotics [ ... ] are used to prevent the threat of anthrax, it will be a huge, you know ..." (P7) "Queue at the pharmacy." (P1)

Moreover, the emotional response of public groups can be a result of over-dramatizing or frightening people with too much or unsuitable information, as was discussed, for example, regarding communication on the long-term risks of contamination:

"There is an effect, if you are directing your communication for the long-term in this kind of regulation, the effect can be contrary to what you want, because you frighten people $[\ldots]$ ]" (P3)

Thus, how much —neither too little nor too much—is said and communicated to publics is critical. Possible scenarios in deciding about communication strategies were also mentioned:

"[ ... ] we need to know the long-term scenarios in health, in reputation, in all the issues which are a challenge for us. Based on that, we can come with a long-term communication strategy $[\ldots]^{\prime \prime}(\mathrm{P} 3)$

Prioritisation of issues in terms of the order and timing of communication was also discussed regarding, in particular, people's health and safety:

“[ ... ] maybe the terror thing isn't the one first thing they need to say something. Yes this is serious. And what is really important for us to say is that, have you been to this station, you need to do that, and then in the end maybe, answer questions about the terrorism. But if the journalists start asking about terror, I think our advice should be, what we are concerned about, are people's health [ ... ]" (P4)

\subsubsection{Weighing Goals and Principles}

When discussing what actions to take and why, some goals and principles underlying certain choices of action were discussed. In the beginning of a crisis, the urgency of communicating something immediately is, for example, justified by the need to make rapid contact with all the parties involved and to take the lead or control over the situation: 
"[ ... ] if you don't say something immediately, you lose control, then you'll be at the back seat, and somebody else takes the lead." (P6)

Moreover, the objective of advising and informing other countries about the situation is to create preparedness, and thus also mitigate the spread of fear. Empowering people to act so as to make them feel in control of their lives after a possibly traumatic experience and enable them to express their emotions in a safe environment was mentioned as an important goal in the later phases of the crisis.

"And if you give people some action to do, they feel they can take back a little bit of control again, it's a psychological aspect of that." (P6)

Reassuring people and helping them to carry on with their lives and addressing their concerns in the long run were also mentioned. This includes accounts by authorities in the aftermath of the situation detailing what the crisis has taught them. According to one expert, a specific strategy is needed to avoid the affected city being subjected to stigma:

"We have to design also a strategy that will help us not to put a stigma on the city as well, because stigmas are really, we know from the radiological accidents, for instance Qoiânia, their economy dropped completely after the accident [ . . . ]" (P7)

Regarding principles, it was pointed out that communication should be constant and take place despite uncertainties:

"You have to communicate when there is a threat to the people, whether you have access to information or not, you have to say something to the public." (P2)

Once information is available, transparency and openness are mentioned in sharing it:

"[ ... ] I don't think that we can have information, and not share it, so I think we should share everything [ ... ] (P5)

Sometimes the principle of openness contradicts with the requirement of providing complete information and necessary facts:

"But complete information, when and why and all this stuff, we have this problem with iodine tablets [ ... ] people have these iodine tablets and they know that they are, they are available there, but then if they don't take them at the moment that we say this to them, they're not useful, so, it's important that we communicate full information about this, not only partial." (P7)

Moreover, messages should be coordinated with other actors in the network to ensure consistency. Ethical principles come into play, for example, in ensuring that all relevant language groups are reached. Emotions should not be forgotten in messages, and sometimes there is a need for direct communication. Finally, timeliness as a principle when deciding about communication with the public was mentioned:

"[ ... ] in a crisis what we all say, you have this golden hour which you have, to need to get your facts straight and to give information to the public [ ... ]" (P5)

\subsubsection{Seeking Guidance from Preparedness Plans, Roles, and Responsibilities}

Not all decisions need to be made in the heat of the moment, but plans can also be made that can guide decision-making during the crisis situation and that may be especially helpful in the beginning of the crisis to activate crisis communication:

" $[\ldots]$ there are all kinds of plans to work with, $[\ldots]$ there are channels to use, for national information, so we are going to do it, we are going to start [ ... ]" (P3) 
Moreover, roles and responsibilities that are defined in preparedness plans and/or readjusted in the beginning of the situation and to some extent re-negotiated as the crisis evolves can also guide decision-making on communication strategies. On communication about a mass funeral, the experts discussed some of the difficulties:

“[ ... ] we are the ones who need to communicate to somebody: 'I am sorry your, your father and sister will not have decent funeral' [ . . ]" (P5)

"Is this our responsibility?" (P3)

"No, we're the ones... (P5)

"I hope it's part of the health strategy." (P3)

"Yes, but we're the ones who have to tell them, how do you do this—by press statement? That's very impersonal." (P5)

Insofar as the crisis situation matches existing plans, communication strategies can also be predefined and relevant stakeholders identified in advance:

"[ ... ] we should not stay in sending information, there is a point, and then you need your strategic plan, and you need your evaluation of the stakeholders, to do on, what moment do you stop sending and..." (P3)

"Start receiving." (P5)

“Precise." (P3)

\section{Discussion}

For analytical clarity, and guided by the formulation of the two research questions, the topic of how communication experts cope with complexity in evolving CBRN terrorism crises was split into two parts: (1) following the evolving situation and (2) making communication strategy choices. To describe this process and to summarize the main findings of this study, a figure is presented (see Figure 1). This may give the impression that the process represents a continuum from 1 to 2 , as it is sometimes described in the literature: situational awareness as "a prelude to decision-making" [5]. This was not, however, the case. Instead, the participants tended to switch back and forth from gathering inputs and interpreting them to deciding about actions, and back again to a situation where more information was needed to further clarify the situation at different points in the evolution of the crisis situation.

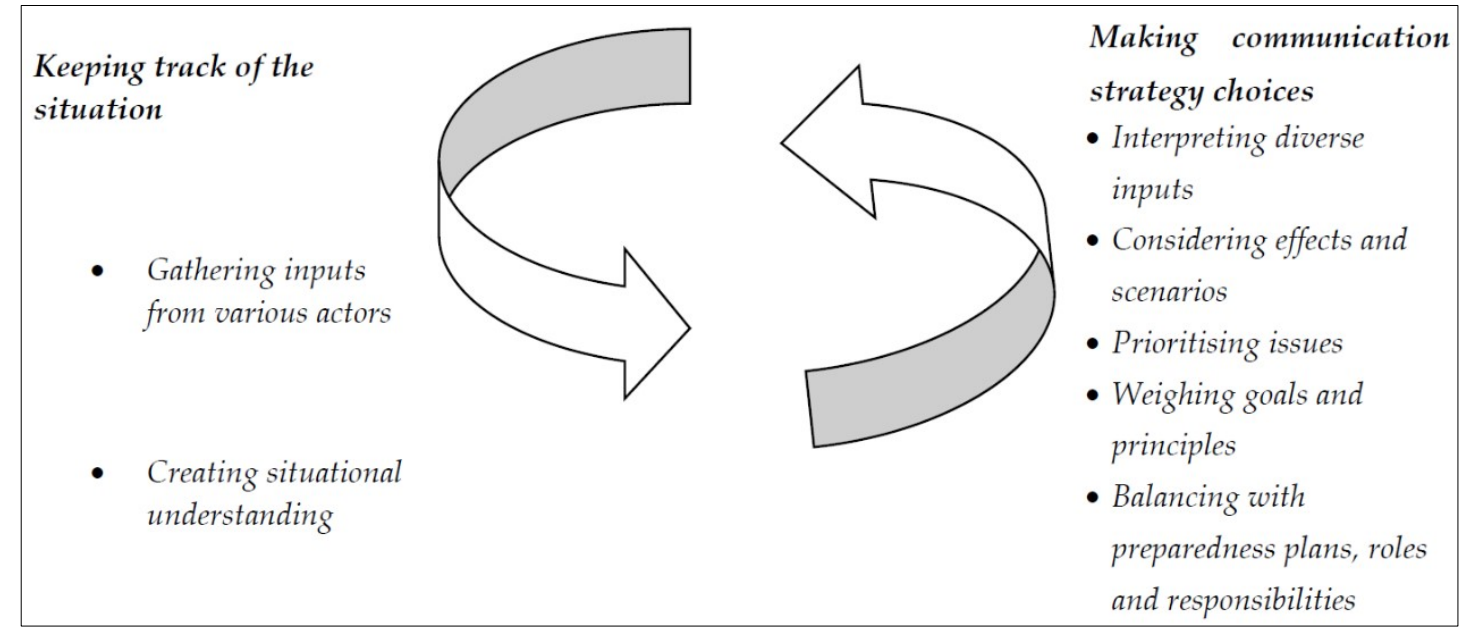

Figure 1. Overview of core elements in coping with complexity in evolving crises. 
Hence, the figure shows that in complex evolving crisis situations, such as those involving CBRN terrorism, coping is a continuous, cyclic process. In the figure, keeping track of the situation and deciding on communication strategies are not separate steps along a linear continuum but overlapping, interacting parts of a dynamic whole. Moreover, the process of strategy-making is decomposed so as to illustrate the core elements involved.

The findings of this study provide insights on how the experts cope with an evolving crisis situation by detailing the core elements involved and illustrating the actual process. The results of the study fit in with a process view on crisis management and underline some recent views about crisis management and communication according to which current crises, such as terrorism, are especially complex, dynamic and challenging [1,2]. As a consequence, crisis teams often operate in challenging conditions, under pressures of uncertainty, stress, and urgency. This results in a situation where a traditional process of planning [10] or ideal models of decision-making may not always apply [5]. To complement preparedness, flexibility in the face of changing circumstances is needed, reflected in what Gilpin and Murphy [25] describe as a complexity perspective and adaptive strategies of (1) remaining continuously informed about evolving conditions; (2) maintaining dynamic networks beyond organisational boundaries; and (3) cultivating flexibility to re-orient and act as a consequence of new circumstances.

While the overall process described in the figure reflects more modern approaches of flexible crisis management and communication, some of its elements are also in line with traditional perspectives [26]. In fact, some views presented by the communication experts continued to express characteristics of older crisis communication thinking ([26], p. 523). For example, guidance was sought in preparedness plans and in previously assigned roles and responsibilities. Therefore, what the figure contains is a combination of traditional and modern views in coping with complexity in evolving crises, such as those involving CBRN terrorism. This is in accordance with Falkheimer and Heide [26], who speak about flexible plans and continuous training.

One could question if the findings of the study are specific for complex crises, such as CBRN terrorism. The process and the core elements might be relevant for other crises also, but they are especially important for the more severe kinds of crises, such as CBRN terrorism, where urgency, emotional overload, high damage potential, and a large response network, among other things, call for a need to have a strong basis in preparedness - but in combination with an ability to stay open and flexible to act in the face of uncertainty, complexity, ambiguity, and evolving conditions. How CBRN terrorism crises evolve is especially difficult to predict, which calls for a high level of flexibility.

\section{Conclusions}

The aim of this study was to clarify how communication experts cope with complexity in evolving and complex crisis situations, such as those involving CBRN terrorism. In particular, the aim was to find out how communication experts follow an evolving situation and how they come to choices about communication strategies during such crises.

The research problem was approached by two research questions which were analysed in the light of data gathered from a table-top discussion among crisis communication experts focusing on a scenario of an anthrax attack. In answer to the first research question it was found that communication experts keep track of the evolving crisis situation by gathering diverse inputs from various actors in the crisis management network as well as from their own sources. Gathering inputs is a process where giving and receiving alternate. Moreover, communication experts create situational understanding by bringing those inputs together in their attempt to clarify the situation and the crisis case at hand. This includes stakeholder analysis, and analysis of the affected publics' information needs, perceptions, reactions, and concerns through, for example, social and news media analysis. Moreover, the experts identify issues, verify information and its sources, and consider different scenarios. The situation at hand is also compared with previous crises of various kinds. 
Regarding the second research question on how communication experts make communication strategy choices in CBRN terrorist crises, it emerged that they interpret various inputs, gained both from the actions and decisions of other crisis management actors as well as from their own analysis of the outside world, in deciding on further actions. Moreover, other factors which count in deciding about communication strategies include timing and the results from stakeholder analyses, including the information needs of affected publics. Communication experts consider the effects of their possible actions along with potential scenarios. Moreover, they try to prioritise issues when deciding about actions, and weigh different goals and principles. Guidance is also sought from preparedness plans, roles, and responsibilities, which are re-negotiated throughout the evolving crisis situation. Hence, it seems that older planning models suggested in the literature are accompanied by more intuitive and flexible ways of constructing communication strategies, consistent with new insights in the literature.

\section{Evaluation of the Study}

Although the fact that the structure of the table-top discussion was kept open can be credited with producing rich and genuine data, some critical afterthoughts should also be mentioned. Rich in nuances, the data was challenging to analyse, and requiring many rounds of reading. Moreover, following at times the pattern of a natural-like interaction in the heat of crisis, the discussion was sometimes hasty due to a sense of urgency, with new topics emerging every now and then. Thus, a more structured approach with more intermediate questions could have allowed the participants to dwell deeper on some issues.

As the research setting consisted of table-top discussions on a realistic scenario, a future study could be conducted to test the findings, and the related figure, in a different setting, including a simulated exercise or a real crisis situation. Moreover, follow-up interviews could complement the results and be used to gain deeper insights into some of the areas discussed and so assist in further developing and fine-tuning the figure.

By shedding light on how communication experts cope with complexity in evolving crisis situations, such as those involving CBRN terrorism, this study makes a contribution towards clarifying core elements in the process of decision-making on communication strategies during an ongoing evolving crisis situation. The results show this process to be a continuous, cyclic one. The underlying process of coping with complexity reflects modern views of flexible crisis management and communication, while traditional preparedness approaches are also relevant. From a praxis perspective, this implies that planning and procedures are needed in combination with continuous training supporting creativity and improvisation. From a theory perspective, to meet communication challenges that are characteristic of more complex crises, CBRN terrorism in particular, a combination of traditional approaches, stressing the functional and instrumental nature of communication, together with modern approaches, emphasizing the role of continuous analysis and adaptation, is relevant. By clarifying the process of communication strategy-making and the core elements involved, the findings of this study provide a more detailed picture of communication strategy-making, thus promoting preparedness and professional resilience in the field.

Acknowledgments: The research leading to these results has received funding from the European Community's Seventh Framework Programme (FP7/2007-2013) under Grant Agreement No. 261693.

Conflicts of Interest: The author declares no conflict of interest.

\section{Abbreviations}

The following abbreviations are used in this manuscript:

CBRN chemical, biological, radiological, nuclear

CATO CBRN Crisis Management, Architecture, Technologies and Operational Procedures 


\section{References}

1. Lagadec, Patrick. "A New Cosmology of Risks and Crises: Time for a Radical Shift in Paradigm and Practice." Review of Policy Research 26 (2009): 473-86.

2. Boin, Arjen. "The New World of Crises and Crisis management: Implications for Policymaking and Research." Review of Policy Research 26 (2009): 367-77. [CrossRef]

3. Beck, Ulrich. "The Terrorist Threat: World Risk Society Revisited." Theory, Culture and Society 19 (2002): 3-55. [CrossRef]

4. Slovic, Paul. “Terrorism as Hazard: A New Species of Trouble." Risk Analysis 22 (2002): 425-26. [CrossRef] [PubMed]

5. Coombs, W. Timothy. "Crisis Communication." In The International Encyclopedia of Communication. Edited by Donsbach Wolfgang. Chichester: Blackwell Publishing, 2008. Available online: http:/ / www.communicationencyclopedia.com/subscriber/tocnode.html?id=g9781405131995_yr2014_ chunk_g97814051319958_ss157-1 (accessed on 9 December 2014).

6. Palttala, Pauliina, and Marita Vos. "Quality Indicators for Crisis Communication to Support Emergency Management by Public Authorities." Journal of Contingencies and Crisis Management 20 (2012): 39-51. [CrossRef]

7. Sellnow, Timothy L., and Matthew W. Seeger. Theorizing Crisis Communication. Chichester: WileyBlackwell, 2013.

8. Reynolds, Barbara, and Matthew W. Seeger. "Crisis and Emergency Risk Communication as an Integrative Model." Journal of Health Communication 10 (2005): 43-55. [CrossRef] [PubMed]

9. Adkins, Gabriel L. "Organizational Networks in Disaster Response: An Examination of the US Government Network's Efforts in Hurricane Katrina." In The Handbook of Crisis Communication. Edited by W. Timothy Coombs and Sherry J. Holladay. Chichester: Blackwell Publishing, 2010, pp. 93-114.

10. Falkheimer, Jesper. "Crisis Communication and Terrorism: The Norway Attacks on 22 July 2011." Corporate Communications: An International Journal 19 (2014): 52-63.

11. Ruggiero, Aino, and Marita Vos. "Terrorism Communication: Characteristics and Emerging Perspectives in the Scientific Literature 2002-2011." Journal of Contingencies and Crisis Management 21 (2013): 153-66. [CrossRef]

12. Rogers, M. Brooke, Richard Amlôt, G. James Rubin, Simon Wessely, and Kristian Krieger. "Mediating the Social and Psychological Impacts of Terrorist Attacks: The Role of Risk Perception and Risk Communication." International Review of Psychiatry 19 (2007): 279-88. [CrossRef] [PubMed]

13. Rubin, G. James, Richard Amlôt, and Lisa Page. "The London Polonium Incident: Lessons in Risk Communications." Health Physics 101 (2011): 545-50. [CrossRef] [PubMed]

14. Rubin, G. James, Richard Amlôt, Lisa Page, and Simon Wessely. "Methodological Challenges in Assessing General Population Reactions in the Immediate Aftermath of a Terrorist Attack." International Journal of Methods in Psychiatric Research 17 (2008): S29-35. [CrossRef] [PubMed]

15. Sheppard, Ben. "Mitigating Terror and Avoidance Behavior through the Risk Perception Matrix to Augment Resilience." Journal of Homeland Security and Emergency Management 8 (2011): 1-21. [CrossRef]

16. Wray, Ricardo J., Matthew W. Kreuter, Heather Jacobsen, Bruce Clements, and R. Gregory Evans. "Theoretical Perspectives on Public Communication Preparedness for Terrorist Attacks." Family and Community Health 27 (2004): 232-41. [CrossRef] [PubMed]

17. Ruggiero, Aino, and Marita Vos. "Social Media Monitoring for Crisis Communication: Process, Methods and Trends in the Scientific Literature." Online Journal of Communication and Media Technologies 4 (2014): 105-30.

18. Kasperson, Roger E., Ortwin Renn, Paul Slovic, Halina S. Brown, Jacque Emel, Robert Goble, Jeanne X. Kasperson, and Samuel Ratick. "The Social Amplification of Risk: A Conceptual Framework." Risk Analysis 8 (1988): 177-87. [CrossRef]

19. Ruggiero, Aino, and Marita Vos. "Communication Challenges in CBRN Terrorism Crises-Expert Perceptions." Journal of Contingencies and Crisis Management 23 (2015): 138-48. [CrossRef]

20. Fischhoff, Baruch. "Communicating about the Risks of Terrorism (Or Anything Else)." American Psychologist 66 (2011): 520-31. [CrossRef] [PubMed] 
21. Griffin-Padgett, Donyale, and Donnetrice Allison. "Making a Case for Restorative Rhetoric: Mayor Rudolph Giuliani and Mayor Ray Nagin's Response to Disaster." Communication Monographs 77 (2010): 376-92. [CrossRef]

22. Vos, Marita, and Henny Schoemaker. Integrated Communication. Concern, Internal and Marketing Communication, 4th ed. Amsterdam: Boom Onderwijs/Lemma, 2011.

23. Business Dictionary. Available online: http://www.businessdictionary.com/definition/strategy.html (accessed on 9 December 2014).

24. Prue, Christine E., Cheryl Lackey, Lisa Swenarski, and Judy M. Gantt. “Communication Monitoring: Shaping CDC's Emergency Risk Communication Efforts." Journal of Health Communication 8 (2003): 35-49. [CrossRef] [PubMed]

25. Gilpin, Dawn R., and Priscilla M. Murphy. "Complexity and Crises: A New Paradigm." In The Handbook of Crisis Communication. Edited by W. Timothy Coombs and Sherry J. Holladay. Chichester: Blackwell Publishing, 2010, pp. 683-90.

26. Falkheimer, Jesper, and Mats Heide. "On Dropping the Tools: From Planning to Improvisation." In The Handbook of Crisis Communication. Edited by W. Timothy Coombs and Sherry J. Holladay. Chichester: Blackwell Publishing, 2010, pp. 511-26.

27. Schwandt, Thomas A. "Sampling logic." In The SAGE Dictionary of Qualitative Inquiry, 3rd ed. Thousand Oaks: SAGE Publications, 2007, pp. 270-72. Available online: http://srmo.sagepub.com/view/the-sagedictionary-of-qualitative-inquiry/SAGE.xml (accessed on 10 May 2016).

28. Schwandt, Thomas A. "Thematic Analysis." In The SAGE Dictionary of Qualitative Inquiry, 3rd ed. Thousand Oaks: SAGE Publications, 2007, p. 292. Available online: http://srmo.sagepub.com/view/the-sagedictionary-of-qualitative-inquiry/SAGE.xml (accessed on 10 May 2016).

29. Ayres, Lisa. "Thematic Coding and Analysis." In The SAGE Encyclopedia of Qualitative Research Methods. Thousand Oaks: SAGE Publications, 2008, pp. 868-69. Available online: http://srmo.sagepub.com/view/ sage-encyc-qualitative-research-methods/n451.xml (accessed on 10 May 2016).

(C) 2016 by the author; licensee MDPI, Basel, Switzerland. This article is an open access article distributed under the terms and conditions of the Creative Commons Attribution (CC-BY) license (http://creativecommons.org/licenses/by/4.0/). 